Check for updates

Cite this: Phys. Chem. Chem. Phys., 2017, 19, 16721

Received 25th April 2017 Accepted 29th May 2017

DOI: $10.1039 / c 7 c p 02722 b$

rsc.li/pccp

\title{
Ion dynamics in halogen-free phosphonium bis(salicylato)borate ionic liquid electrolytes for lithium-ion batteries $\dagger$
}

\author{
Faiz Ullah Shah, (D)*a Oleg I. Gnezdilov (D) ${ }^{b}$ and Andrei Filippov (D)*ab
}

\begin{abstract}
This study was focused on the investigation of ion dynamics in halogen-free, hydrophobic, and hydrolytically stable phosphonium bis(salicylato)borate $\left[\mathrm{P}_{4,4,4,8}\right][\mathrm{BSCB}]$ ionic liquid electrolytes for lithium-ion batteries. The structure and purity of the synthesized ionic liquid and lithium bis(salicylato)borate $\mathrm{Li}[\mathrm{BSCB}]$ salt were characterized using ${ }^{1} \mathrm{H},{ }^{13} \mathrm{C},{ }^{31} \mathrm{P}$, and ${ }^{11} \mathrm{~B} N M R$ spectroscopy. The Li[BSCB] salt was mixed with an ionic liquid at the concentrations ranging from $2.5 \mathrm{~mol} \%$ to $20 \mathrm{~mol} \%$. The physicochemical properties of the resulting electrolytes were characterized using thermal analysis (TGA and DSC), electrical impedance spectroscopy, and pulsed-field gradient (PFG) NMR and ATR-FTIR spectroscopy. The apparent transfer numbers of the individual ions were calculated from the diffusion coefficients of the cation and anion as determined via the PFG NMR spectroscopy. NMR and ATR-FTIR spectroscopic techniques revealed dynamic interactions between the lithium cation and bis(salicylato)borate anion in the electrolytes. The ion-ion interactions were found to increase with the increasing concentration of the $\mathrm{Li}[\mathrm{BSCB}]$ salt, which resulted in ionic clustering at the concentrations higher than $15 \mathrm{~mol} \%$ of $\mathrm{Li}$ salt in the ionic liquid.
\end{abstract}

\section{Introduction}

Over the past decade, an exponentially growing interest has been seen in the use of electrical energy storage devices not only for portable consumer electronics but also for transportation technologies including buses, trams, cars, and motorcycles. Lithium-ion batteries play an important role in modern electronics due to their high energy density. ${ }^{1}$ The conventional organic electrolytes have a number of drawbacks such as volatility, tedious purification process, higher environmental impact, flammability, and low ionic conductivity. ${ }^{2}$ These problems are limiting their applicability in lithium-ion batteries in terms of safety and performance. For example, the most common conventional electrolyte used in the commercially available lithium-ion batteries is the $\mathrm{LiPF}_{6}$ salt dissolved in a mixture of ethylene carbonate (EC) and diethyl carbonate (DEC). ${ }^{3,4} \mathrm{LiPF}_{6}$ is thermally unstable and decomposes at elevated temperatures, producing $\mathrm{LiF}$ and $\mathrm{PF}_{5}$. $\mathrm{PF}_{5}$ is proven to undergo hydrolysis, forming $\mathrm{HF}$ and $\mathrm{PF}_{3} \mathrm{O}$ that are highly reactive to both positive and negative electrodes. ${ }^{5}$ Extensive research efforts are being made to develop novel and safe electrolytes for lithium-ion batteries to improve the safety of

\footnotetext{
${ }^{a}$ Chemistry of Interfaces, Luleå University of Technology, Luleå, SE-97187, Sweden. E-mail:faisha@ltu.se, Andrei.Filippov@ltu.se

${ }^{b}$ Institute of Physics, Kazan Federal University, 420008 Kazan, Russia

$\dagger$ Electronic supplementary information (ESI) available. See DOI: 10.1039/ c7cp02722b
}

the energy storage devices. Ionic liquids possess a combination of properties that makes them excellent electrolytes for batteries in terms of enhanced performance, safety, and stability. ${ }^{6}$

Ionic liquids (ILs) are salts composed of cations and anions and are liquids at or below $100{ }^{\circ} \mathrm{C}^{7}$ Some of their properties include high polarity, non-volatility, high thermal stability, high ionic conductivity, and high chemical and electrochemical stability; moreover, they remain liquid over a wide temperature range. These properties can be tuned to optimize their performance for a variety of applications. The design potential originates from a large number of possible cations and anions that can be combined into an almost unlimited number of ionic liquids., Due to the unique physicochemical properties of ILs, they are considered as the most suitable replacement for the organic electrolytes currently used in lithium batteries. ${ }^{10}$ The potential of a variety of ILs as electrolytes for lithium-ion batteries has been investigated during the past decade. ${ }^{11}$ Most of these ionic liquid electrolytes contain halogenated anions and different cations including pyrrolidinium, imidazolium, choline, and phosphonium. ${ }^{12-15}$

There are a number of limitations of the conventional ionic liquid electrolytes that need to be tackled to improve the safety and performance of lithium-ion batteries. ${ }^{16,17}$ (1) Most of the ionic liquid electrolytes contain halogenated anions such as $\mathrm{BF}_{4}{ }^{-}, \mathrm{PF}_{6}{ }^{-}$, etc., which are sensitive to moisture and thus produce toxic and corrosive products upon hydrolysis. Therefore, halogen-free ionic liquid electrolytes are desirable for 
improving the safety and performance of the batteries. (2) There should be weak interactions between $\mathrm{Li}^{+}$and the anion of the ionic liquid to achieve fast ionic mobility between electrodes. (3) The ionic liquid electrolytes should be hydrophobic with low affinity to water to enhance the battery life. Very little attention has been devoted to the design of new salts and ionic liquids as electrolytes for lithium device applications.

A great interest in the use of halogen-free orthoborate-based lithium salts and their derivatives, including lithium bis[1,2benzenediolato(2-)-O,O' $]$ borate $\mathrm{Li}[\mathrm{BBB}]{ }^{18}$ lithium bis[2,3-naphthalene-diolato(2-)-O, $\left.\mathrm{O}^{\prime}\right]$ borate $\mathrm{Li}[\mathrm{BNB}],{ }^{19}$ lithium bis[2,2-biphenyldiolato(2-)-O, $\mathrm{O}^{\prime}$ ]borate $\mathrm{Li}[\mathrm{BBPB}]{ }^{20}$ lithium bis[croconato]borate $\mathrm{Li}[\mathrm{BCB}],^{21}$ and lithium bis(salicylato)borate $\mathrm{Li}[\mathrm{BScB}],^{22,23}$ as potential candidates for lithium batteries has been noticed. All these orthoborate anions have shown an extensive charge delocalization due to their strong electron-withdrawing substituents. This is one of the main reasons for the high ionic conductivity, wide electrochemical stability window, and high thermal stability of these orthoborate anions. Aromaticity of these orthoborate anions is another reason for their stability. The salts based on these anions, also known as Hückel anions, are promising electrolytes for lithium batteries, providing excellent electrochemical properties as compared to other similar salts. $^{24,25}$

Some other orthoborate-based lithium salts that are not aromatic have been extensively investigated for their applications in lithium batteries. These anions include lithium bis(malonato)borate, lithium bis(oxalato)borate, and their derivatives. ${ }^{26,27}$ It has been found that $\mathrm{Li}[\mathrm{BOB}]$ dissolved in 1-ethyl-3-methyl-imidazolium tetrafluoroborate IL is a promising electrolyte for rechargeable lithium batteries using a lithium alloy anode. ${ }^{28}$ Over the past few decades, a number of studies have reported that $\mathrm{Li}[\mathrm{BOB}]$ possesses unique electrochemical properties that make this salt an attractive alternative electrolyte for lithium-ion batteries. ${ }^{29-34}$

Despite the excellent electrochemical properties of orthoborate anions, not much attention has been paid to the ion dynamic mechanisms of these anions as electrolytes for lithium batteries. To the best of our knowledge, this is the first report on the investigation of ion dynamics of orthoborate-based ionic liquid electrolytes via electrical impedance spectroscopy (EIS) and pulsed-field gradient (PFG) NMR spectroscopy. EIS provides information about the overall ion transport, whereas PFG NMR spectroscopy allows the determination of individual selfdiffusion coefficients of the cations and anions. A combination of these two techniques provides deeper insights into the ion dynamics in ionic liquid electrolytes. In this study, we investigated the mechanism of ion dynamics in halogen-free and hydrolytically stable electrolytes based on tributyloctylphosphonium bis(salicylato)borate $\left[\mathrm{P}_{4,4,4,8}\right][\mathrm{BScB}]$ IL mixed with a lithium bis(salicylato)borate $\mathrm{Li}[\mathrm{BScB}]$ salt. The structures and abbreviations of the cation and anion of the ionic liquid are shown in Fig. 1. The $\mathrm{Li}[\mathrm{BScB}]$ salt was dissolved in the IL at various concentrations ranging from $2.5 \mathrm{~mol} \%$ to $20 \mathrm{~mol} \%$. The investigation of the physical and transport properties as a function of lithium salt concentration in $\left[\mathrm{P}_{4,4,4,8}\right][\mathrm{BScB}]$ IL was carried out using ionic conductivity,

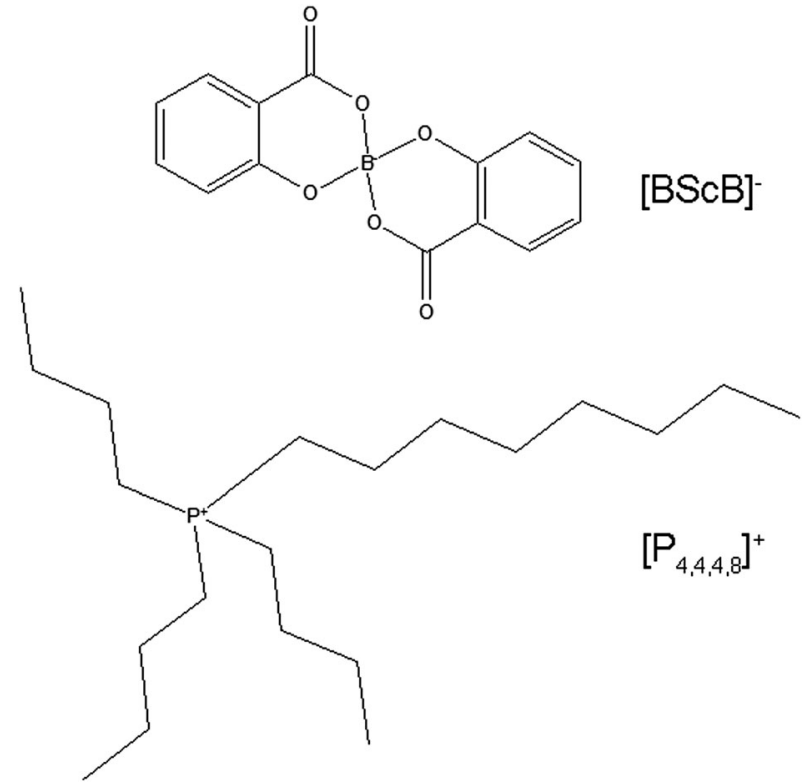

Fig. 1 Structures and abbreviations of the ionic components of the halogen-free ionic liquid.

thermal analysis, FT-IR spectroscopy, and PFG NMR measurements.

\section{Experimental}

\section{Sample preparation}

The ionic liquid $\left[\mathrm{P}_{4,4,4,8}\right][\mathrm{BScB}]$ and lithium salt $\mathrm{Li}[\mathrm{BScB}]$ were synthesized as described in our previous publication. ${ }^{35}$ The structure and purity of the products were confirmed using ${ }^{1} \mathrm{H},{ }^{13} \mathrm{C},{ }^{31} \mathrm{P}$, and ${ }^{11} \mathrm{~B}$ NMR spectroscopy. All the NMR spectra are provided in the ESI. $\dagger$ A total of six electrolyte samples were prepared via the dissolution of $\mathrm{Li}[\mathrm{BScB}]$ salt in $\left[\mathrm{P}_{4,4,4,8}\right][\mathrm{BScB}] \mathrm{IL}$ in different concentrations ranging from $2.5 \mathrm{~mol} \%$ to $20 \mathrm{~mol} \%$. A maximum solubility of $20 \mathrm{~mol} \%$ of $\mathrm{Li}[\mathrm{BScB}]$ salt in $\left[\mathrm{P}_{4,4,4,8}\right][\mathrm{BScB}]$ IL was obtained at room temperature without crystallization. All the samples were dried in a vacuum oven at $60{ }^{\circ} \mathrm{C}$ for more than 2 days before performing the experiments. Water content was determined via Karl Fischer titration using 917 coulometer (Metrohm). Triplicate measurements were performed, and the mean values have been reported together with standard deviation (SD). The water content of the neat $\left[\mathrm{P}_{4,4,4,8}\right][\mathrm{BScB}]$ was $0.039 \% \pm 0.002$. The composition and water content of the electrolytes are shown in Table 1.

\section{Nuclear magnetic resonance spectroscopy}

The structure and purity of the synthesized lithium salt and ionic liquid were characterized using Bruker Ascend Aeon WB 400 (Bruker BioSpin AG, Fällanden, Switzerland) NMR spectrometer. DMSO and $\mathrm{CDCl}_{3}$ were used as solvents for the lithium salt and ionic liquid, respectively. The working frequency was 400.21 MHz for ${ }^{1} \mathrm{H}, 100.63 \mathrm{MHz}$ for ${ }^{13} \mathrm{C}, 162.01 \mathrm{MHz}$ for 
Table 1 Composition and water content of the electrolytes employed in this study

\begin{tabular}{llll}
\hline $\begin{array}{l}\mathrm{mol} \% \\
\text { of } \mathrm{Li}[\mathrm{BScB}]\end{array}$ & $\begin{array}{l}\text { mol\% of } \\
{\left[\mathrm{P}_{4,4,4,8}\right][\mathrm{BScB}]}\end{array}$ & $\begin{array}{l}\text { Molality } \\
\left(\mathrm{mol} \mathrm{kg}^{-1}\right)\end{array}$ & $\begin{array}{l}\text { Water content } \\
(\%) \pm \mathrm{SD}\end{array}$ \\
\hline 2.5 & 97.5 & 0.043 & $0.050 \pm 0.003$ \\
5 & 95 & 0.088 & $0.066 \pm 0.004$ \\
7.5 & 92.5 & 0.140 & $0.034 \pm 0.002$ \\
10 & 90 & 0.186 & $0.035 \pm 0.005$ \\
15 & 85 & 0.295 & $0.083 \pm 0.008$ \\
20 & 80 & 0.418 & $0.067 \pm 0.006$
\end{tabular}

${ }^{31} \mathrm{P}$, and $128.40 \mathrm{MHz}$ for ${ }^{11} \mathrm{~B}$. Data were processed using the Bruker Topspin 3.5 software.

\section{Pulsed-field gradient diffusometry}

Pulsed-field gradient (PFG) NMR measurements were performed using a Bruker Avance III (Bruker Biospin AG, Fällanden, Switzerland) NMR spectrometer. The working frequency was $400.27 \mathrm{MHz}$ for ${ }^{1} \mathrm{H}$ and $155.56 \mathrm{MHz}$ for ${ }^{7} \mathrm{Li}$. Data were processed using the Bruker Topspin 3.1 software. NMR self-diffusion measurements were performed via $^{1} \mathrm{H}$ with a PFG NMR probe Diff50 (Bruker) with a maximum amplitude of the magnetic field gradient pulse of $30 \mathrm{~T} \mathrm{~m}^{-1}$. The sample was placed in a standard $5 \mathrm{~mm}$ glass sample tube and closed with a plastic stopper to avoid contact with air. Prior to measurements, the sample was equilibrated at a specific temperature for $30 \mathrm{~min}$.

Details of the PFG NMR technique used for measuring the molecular diffusion coefficients can be found in the literature. ${ }^{36}$ The primary information for the diffusion is contained in the diffusion decay (DD) of the NMR stimulated echo amplitude $A$. For the stimulated echo pulse sequence used, diffusion decay of $A$ in the case of the simple non-associating molecular liquid can be described by the following equation: ${ }^{37}$

$$
A\left(g, \delta, t_{\mathrm{d}}\right)=A(0) \exp \left(-\gamma^{2} g^{2} \delta^{2} D t_{\mathrm{d}}\right)
$$

where $A(0)$ is the factor proportional to the proton content in the system and to the spin-lattice and spin-spin relaxation times, $\gamma$ is the gyromagnetic ratio for a used nucleus; $g$ and $\delta$ are the amplitude and duration of the gradient pulse; $t_{\mathrm{d}}$ is the diffusion time; and $D$ is the self-diffusion coefficient. In our experiments, $t_{\mathrm{d}}$ was in the range $4-100 \mathrm{~ms}$ for ${ }^{1} \mathrm{H}$ diffusion, whereas $t_{\mathrm{d}}$ was in the range $200-700 \mathrm{~ms}$ for ${ }^{7} \mathrm{Li}$ diffusion. Timedependent diffusion was not observed.

\section{Thermal analysis}

Thermogravimetric analysis (TGA) was performed using a Perkin Elmer 8000 TGA apparatus. Temperature-ramped TGA experiments were carried out at a heating rate of $10{ }^{\circ} \mathrm{C} \mathrm{min}^{-1}$. Herein, 2-4 mg of the ionic liquid sample was used for each experiment. All the TGA experiments were performed using nitrogen gas as the inert carrier gas.

Differential scanning calorimetry (DSC) experiments were performed using a Perkin Elmer DSC 6000 apparatus. About 2-5 $\mathrm{mg}$ of the ionic liquid sample was packed in an aluminium pan for each experiment. DSC data were obtained during both cooling and heating cycles in the temperature range from $-70{ }^{\circ} \mathrm{C}$ to $100{ }^{\circ} \mathrm{C}$ at the scanning rate of $10{ }^{\circ} \mathrm{C} \mathrm{min}^{-1}$. The glass transition temperatures $T_{\mathrm{g}}$ were determined as the onset of the transition on the DSC graphs. An inert nitrogen gas was supplied to the instrument at a constant flow of $20 \mathrm{~mL} \mathrm{~min}^{-1}$ to preserve a dry environment inside the sample chamber.

\section{Ionic conductivity}

The ionic conductivity of the electrolytes was measured using a Metrohm Autolab PGSTAT302N electrochemical workstation with the FRA32M module for impedance measurements controlled by the Nova 2.02 software. A frequency range from $1 \mathrm{~Hz}$ to $1 \mathrm{MHz}$ with an AC voltage amplitude of $50 \mathrm{mV}_{\mathrm{rms}}$ was used for the measurements. A $70 \mu \mathrm{L}$ closed cell ( $70 \mu \mathrm{L}$ solvent) from RHD instruments was used for the measurements. The measurements were performed in temperature range from $0{ }^{\circ} \mathrm{C}$ to $100{ }^{\circ} \mathrm{C}$ within an uncertainty of $\pm 0.1{ }^{\circ} \mathrm{C}$. A two-electrode setup was used for the ionic conductivity measurements. Pt-wire with a diameter of $0.25 \mathrm{~mm}$ was used as the working electrode, and a $70 \mu \mathrm{L}$ platinum crucible served as the sample container as well as a counter electrode. Both electrodes were polished with a Kemet diamond paste $0.25 \mu \mathrm{m}$ prior to each measurement. The cell constant of the conductivity cell was determined via a $100 \mu \mathrm{S} \mathrm{cm} \mathrm{cm}^{-1} \mathrm{KCl}$ standard solution $\left(\right.$ Kcell $=17.511 \mathrm{~cm}^{-1}$ ) obtained from Metrohm. The cell was thermally equilibrated for at least $20 \mathrm{~min}$ before each measurement.

\section{Infrared spectroscopy}

Attenuated total reflection Fourier transform infrared (ATR-FTIR) spectra were obtained using a Bruker IFS 80v vacuum Fourier transform infrared spectrometer equipped with a deuterated triglycine sulphate (DTGS) detector and diamond ATR accessory. All spectra were obtained at room temperature $\left(\sim 22{ }^{\circ} \mathrm{C}\right)$ using the double side forward-backward acquisition mode. A total number of 256 scans were co-added and signal-averaged at an optical resolution of $4 \mathrm{~cm}^{-1}$.

\section{Results and discussion}

Fig. 2 represents the DSC heating traces of the neat $\left[\mathrm{P}_{4,4,4,8}\right][\mathrm{BScB}]$ and $\left[\mathrm{P}_{4,4,4,8}\right][\mathrm{BScB}]$ mixed with various concentrations of $\mathrm{Li}[\mathrm{BScB}]$. The neat $\left[\mathrm{P}_{4,4,4,8}\right][\mathrm{BScB}]$ reveals the glass transition temperature $\left(T_{\mathrm{g}}\right)$ at $230 \mathrm{~K}$, which is in a good agreement with that reported in literature. ${ }^{35}$ The glass transition temperatures are strongly affected by the addition of lithium salt to the IL. A decrease in the glass transition temperature is observed when $\mathrm{Li}[\mathrm{BScB}]$ salt is added to the IL. The $T_{\mathrm{g}}$ value increases from $230 \mathrm{~K}$ for the neat IL to $250 \mathrm{~K}$ for the sample with $20 \mathrm{~mol} \%$ of lithium salt in the IL. An increase in $T_{\mathrm{g}}$ has been previously observed upon the addition of lithium or sodium salt to ILs. ${ }^{38}$ The increase in $T_{\mathrm{g}}$ upon the addition of lithium salt is due to the increase in the ion-ion attractions that lead to higher glass transition temperatures. ${ }^{39}$

The thermal stability of the neat $\left[\mathrm{P}_{4,4,4,8}\right][\mathrm{BScB}]$ and $\left[\mathrm{P}_{4,4,4,8}\right][\mathrm{BScB}]$ mixed with $\mathrm{Li}[\mathrm{BSCB}]$ salt was investigated using thermogravimetric 


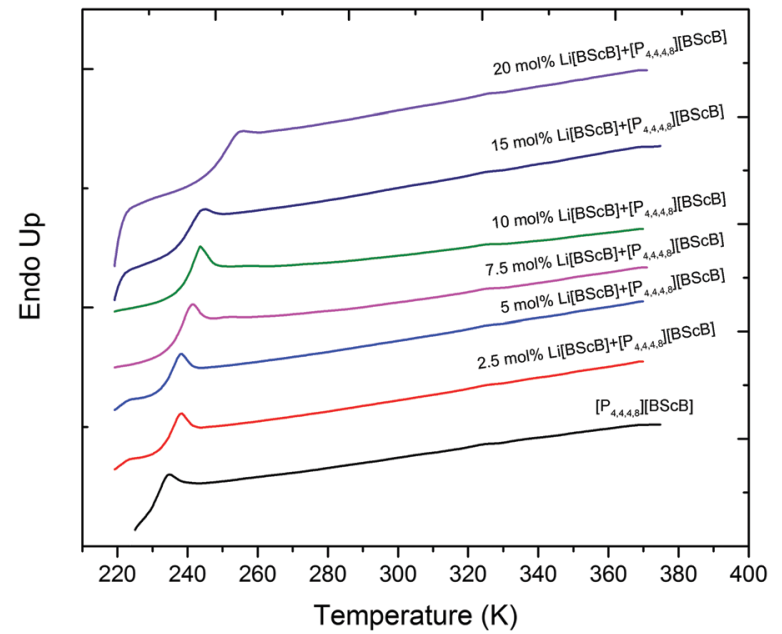

Fig. 2 DSC curves for neat $\left[P_{4,4,4,8}\right][B S C B]$ and $\left[P_{4,4,4,8}\right][B S c B]$ with different concentrations (mol\%) of $\mathrm{Li}[\mathrm{BSCB}]$ salt.

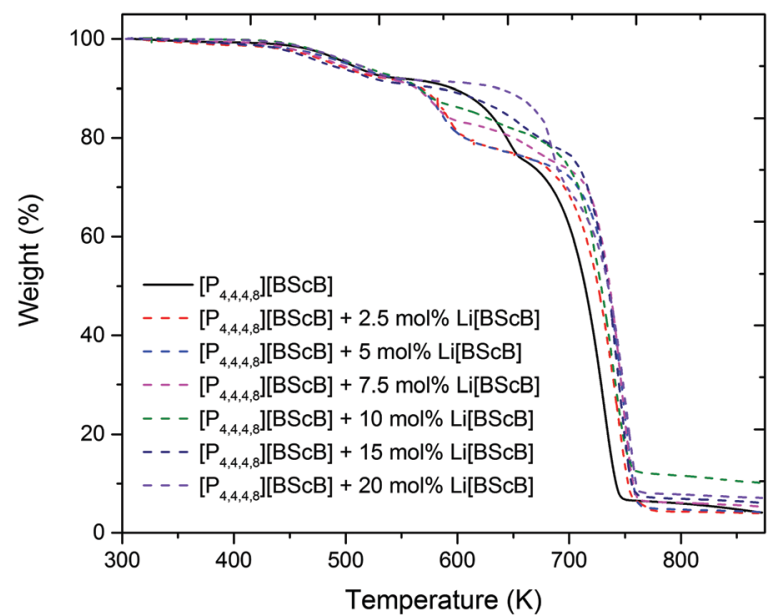

Fig. 3 TGA thermograms of neat $\left[P_{4,4,4,8}\right][B S c B]$ and $\left[P_{4,4,4,8}\right][B S c B]$ with different concentrations (mol\%) of Li[BScB] salt.

analysis. The variable-temperature TGA data for neat $\left[\mathrm{P}_{4,4,4,8}\right][\mathrm{BScB}]$ (solid black line) and $\left[\mathrm{P}_{4,4,4,8}\right][\mathrm{BScB}]$ mixed with $\mathrm{Li}[\mathrm{BScB}]$ salt (dotted coloured lines) are shown in Fig. 3. The TGA data for the neat $\left[\mathrm{P}_{4,4,4,8}\right][\mathrm{BScB}]$ reveal that major weight loss occurs in two steps; the onset temperature of the first step of decomposition is at $c a .450 \mathrm{~K}$ and the onset of the second step is at $c a .600 \mathrm{~K}$. The addition of $\mathrm{Li}[\mathrm{BScB}]$ salt has no significant effect on the first thermal process; however, a slight effect is observed on the second thermal process. It is clearly seen that the second thermal process occurs at lower temperatures when up to $10 \mathrm{~mol} \%$ of $\mathrm{Li}[\mathrm{BScB}]$ salt is added to the IL. However, the second thermal decomposition is delayed in the case of the samples with concentrations higher than $10 \mathrm{~mol} \%$ of $\mathrm{Li}[\mathrm{BScB}]$ salt in the IL. Particularly, the electrolytes with $15 \mathrm{~mol} \%$ and $20 \mathrm{~mol} \%$ of $\mathrm{Li}[\mathrm{BScB}]$ salt in the IL have shown slightly higher thermal stability as compared to the neat IL and IL with lower Li salt concentrations.

The ionic conductivities of the neat $\left[\mathrm{P}_{4,4,4,8}\right][\mathrm{BScB}]$ and $\left[\mathrm{P}_{4,4,4,8}\right][\mathrm{BScB}]$ with various concentration of the $\mathrm{Li}[\mathrm{BScB}]$ salt
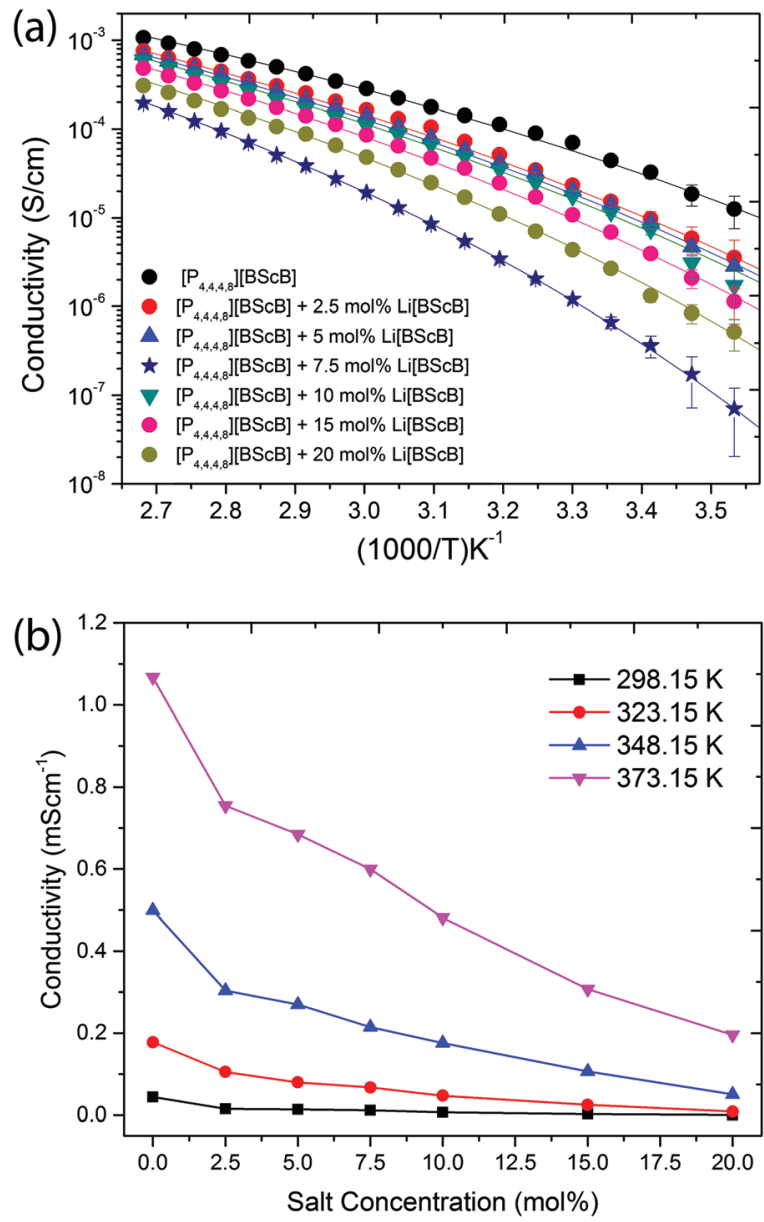

Fig. 4 (a) Arrhenius plot of ionic conductivity for $\left[P_{4,4,4,8}\right][B S C B]$ with different $\mathrm{Li}[\mathrm{BSCB}]$ concentrations, as indicated $(\mathrm{mol} \%)$, and their best fittings using the VFT equation. The error bars for most of the points are contained within the size of the data points. (b) Dependence of ionic conductivity on the $\mathrm{Li}[\mathrm{BSCB}]$ concentration at various temperatures.

are shown in Fig. 4. Fig. 4a represents the Arrhenius plot of conductivity and Fig. 4b demonstrates the concentrationdependent ionic conductivity at various temperatures. As expected, the ionic conductivity increases with the increase in temperature for all the systems examined herein, whereas it decreases across the entire measured temperature range with the increase in the concentration of Li salt. The decrease in the ionic conductivity with the addition of lithium salt is due to the increase in the viscosity of the electrolyte. An increase in viscosity upon the addition of lithium salt is expected due to stronger ionic bonds in the electrolyte, slowing down the mobility of ions in the liquid. One of the reasons for this decrease in the ionic mobility is the stronger Coulombic interactions between small lithium ions and the bis(salicylato)borate anions as compared to the interactions between the larger phosphonium cations and the bis(salicylato)borate anions. Thus, the decrease in ionic conductivity with the addition of lithium salts is due the stronger Coulombic interactions that lead to a decrease in the ionic mobility of the electrolytes. 
For the ionic conductivity of the ILs, the Vogel-FulcherTammann (VFT) equation is

$$
\sigma=\sigma_{0} \exp \left(\frac{-B}{\left(T-T_{0}\right)}\right)
$$

where $\sigma_{0}, B$, and $T_{0}$ are the fitting parameters: pre-exponential factor, a factor related to the activation energy, and the ideal glass transition temperature, respectively. $T_{0}$ indicates a temperature at which free volume and mobility is reduced to zero. ${ }^{40}$ Energy of activation for the ionic conductivity is related to $B$ as $E_{\sigma}=B \cdot R$. The fitting procedure was performed in two steps. In the first step, we plotted $\ln (\sigma)$ viz. $1 /\left(T-T_{0}\right)$ and selected $T_{0}$ to have a linear dependence. Uncertainty in this step was $\pm 10 \mathrm{~K}$. In the second step, we fitted the dependence via a linear regression to obtain fitting parameters $\left(\sigma_{0}, B\right)$. The temperature dependence of the ionic conductivity for $\left[\mathrm{P}_{4,4,4,8}\right][\mathrm{BScB}]$ with different $\mathrm{Li}[\mathrm{BScB}]$ concentrations fitted well with the VFT model over the temperature range studied herein. The VFT parameters for the ionic conductivity are summarized in Table 2 .

The $T_{\mathrm{g}}$ values extracted from the DSC curves are larger for neat $\left[\mathrm{P}_{4,4,4,8}\right][\mathrm{BScB}]$ and IL mixed with $\mathrm{Li}[\mathrm{BScB}]$ salt as compared to the reference $T_{0}$ values. The $T_{\mathrm{g}}-T_{0}$ values are in the range from $55 \mathrm{~K}$ to $75 \mathrm{~K}$, and the $T_{0} / T_{\mathrm{g}}$ values are in the range from 0.70 to 0.76 . The $T_{\mathrm{g}}$ values are always larger than the vitreous transition temperature $\left(T_{\mathrm{g}}>T_{0}\right)$, and according to an empirical approximation, the $T_{0} / T_{\mathrm{g}} \approx 0.75$ and $T_{\mathrm{g}}-T_{0} \approx 50 \mathrm{~K}$ for ionic liquids. ${ }^{41}$ The larger $T_{\mathrm{g}}-T_{0}$ values have been previously reported for ionic liquid electrolytes, suggesting decoupling of the conductivity from $T_{\mathrm{g}}$ and onset of ionic mobility at temperatures below the glass transition temperature. ${ }^{42}$

PFG NMR spectroscopy was employed to obtain further insights into the ionic mobility of the ions in the electrolytes. High intensity NMR signals were obtained for $\left[\mathrm{P}_{4,4,4,8}\right]^{+}$cation, $[\mathrm{BScB}]^{-}$anion, and $\mathrm{Li}^{+}$cation. Diffusion decays were easily measured in the dynamic range of up to 3-4 decimal orders. Therefore, the achieved uncertainties in the diffusion coefficients were in the range of $0.2-2.1 \%$. This was estimated from the distribution of points in diffusion decays and from the reproducibility of the values of diffusion coefficients in consequent series of measurements.

Fig. 5 demonstrates a monotonous increase of diffusivities with temperature that does not perfectly follow the Arrhenius dependence. As expected, diffusivity of $[\mathrm{BScB}]^{-}$anion is always slightly (by factor 1.03-1.14) higher than that of $\left[\mathrm{P}_{4,4,4,8}\right]^{+}$cation due to the smaller size of the anion. $\mathrm{Li}^{+}$diffusivity is lowered by

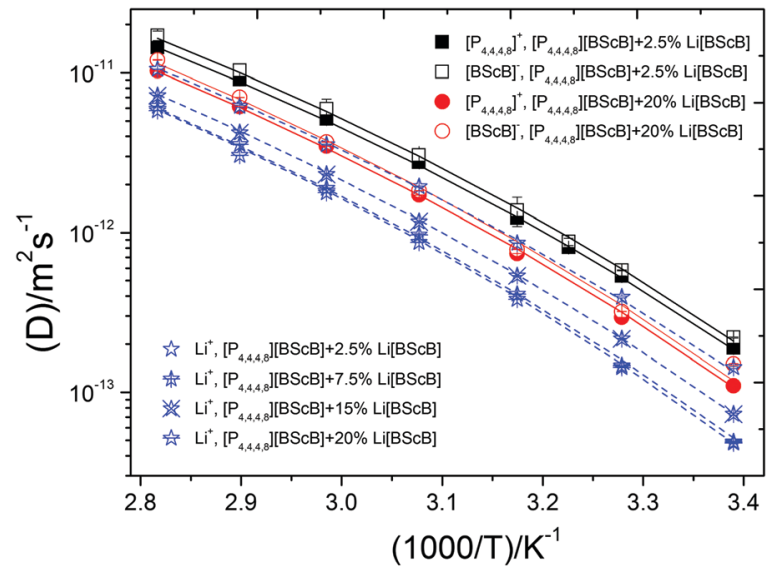

Fig. 5 Arrhenius plot of diffusion coefficients of ions in the IL containing different molar concentrations of the $\mathrm{Li}[\mathrm{BSCB}]$ salt and their best fittings using the VFT equation. The error bars for the most of data points are contained within the size of the points.

a factor of $\sim 2.3$ as compared to the $\left[\mathrm{P}_{4,4,4,8}\right]^{+}$and $[\mathrm{BScB}]^{-}$ diffusivity. It was found that increase in the concentration of the $\mathrm{Li}[\mathrm{BScB}]$ salt in the IL leads to a monotonous decrease in the mobilities of all the three ions present in the system.

Arrhenius type of equation, ${ }^{43}$ which describes the temperature dependence of $D_{\mathrm{s}}$, has a form

$$
D(T)=D_{0} \cdot \exp \left(\frac{-E_{\mathrm{D}}}{R T}\right)
$$

where $D_{0}$ is a parameter that is independent of temperature and $E_{\mathrm{D}}$ is the molar activation energy of diffusion. Arrhenius function shows a linear dependence in Arrhenius coordinates. However, this is not the case of our system, as seen in Fig. 5. Non-Arrhenius dependences are typical for ionic liquids. ${ }^{44}$ The VFT equation in the form for diffusivity is more universal form of temperature dependences, which considers proximity of the system temperature to their glass transition temperature $T_{0}$. This form is equivalent to the Arrhenius dependence in the high-temperature limit: ${ }^{44}$

$$
D=D_{0} \exp \left(\frac{-B}{\left(T-T_{0}\right)}\right)
$$

where $D_{0}, T_{0}$, and $B$ are adjustable parameters. Energy of activation for diffusion is related to $B$ as $E_{\mathrm{D}}=B \cdot R$. We have described $D(T)$ in Fig. 5 by fitting $D_{0}, T_{0}$, and $B$. Moreover, as in the case of conductivity, the fitting procedure was performed in

\begin{tabular}{|c|c|c|c|c|c|c|}
\hline Li[BScB] (mol\%) & $\sigma_{0}\left(\mathrm{~S} \mathrm{~cm}^{-1}\right)$ & $B(\mathrm{~K})$ & $T_{0}(\mathrm{~K})$ & $E_{\sigma}\left(\mathrm{kJ} \mathrm{mol}{ }^{-1} \mathrm{~K}^{-1}\right)$ & $T_{\mathrm{g}}$ (onset) (K) & $T_{\mathrm{g}}($ midpoint $)(\mathrm{K})$ \\
\hline 0.0 & $0.20 \pm 0.01$ & $1041 \pm 8$ & $175 \pm 10$ & $8.7 \pm 0.1$ & 230 & 235 \\
\hline 2.5 & $0.34 \pm 0.02$ & $1200 \pm 9$ & $175 \pm 10$ & $10.0 \pm 0.1$ & 233 & 238 \\
\hline 5.0 & $0.38 \pm 0.01$ & $1296 \pm 7$ & $175 \pm 10$ & $10.8 \pm 0.1$ & 235 & 240 \\
\hline 7.5 & $0.44 \pm 0.06$ & $1350 \pm 8$ & $175 \pm 10$ & $11.2 \pm 0.1$ & 237 & 241 \\
\hline 10.0 & $0.46 \pm 0.02$ & $1425 \pm 10$ & $175 \pm 10$ & $11.8 \pm 0.1$ & 239 & 243 \\
\hline 15.0 & $0.50 \pm 0.03$ & $1560 \pm 13$ & $175 \pm 10$ & $13.0 \pm 0.1$ & 240 & 244 \\
\hline 20.0 & $0.79 \pm 0.10$ & $1867 \pm 7$ & $175 \pm 10$ & $15.5 \pm 0.1$ & 250 & 254 \\
\hline
\end{tabular}

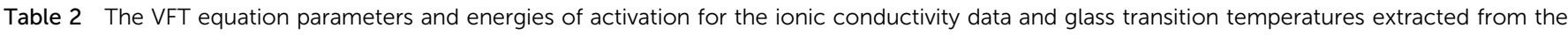
DSC traces for the neat $\left[\mathrm{P}_{4,4,4,8}\right][\mathrm{BSCB}]$ and $\left[\mathrm{P}_{4,4,4,8}\right][\mathrm{BSCB}]$ mixed with different $\mathrm{Li}[\mathrm{BSCB}]$ concentrations 
two steps. In the first step, we plotted $\ln (D)$ viz. $1 /\left(T-T_{0}\right)$ and selected $T_{0}$ to have a linear dependence. Uncertainty in this step was $\pm 10 \mathrm{~K}$. In the second step, we fitted the dependence by a linear regression to obtain fitting parameters $\left(D_{0}, B\right)$. Best results of the fitting are shown by solid lines in Fig. 5, and the corresponding fitting parameters are presented in Table 3.

From the Table 3, we can see that the difference in the diffusion of ions in $\left[\mathrm{P}_{4,4,4,8}\right][\mathrm{BScB}]$ containing $\mathrm{Li}[\mathrm{BScB}]$ salt is mainly related to the activation energy $E_{\mathrm{D}}$. For the electrolyte containing $2.5 \mathrm{~mol} \%$ and $20 \mathrm{~mol} \%$ of $\mathrm{Li}[\mathrm{BScB}], D_{0}$ are in the order $T_{0}\left(\mathrm{Li}^{+}\right)<T_{0}\left(\left[\mathrm{P}_{4,4,4,8}\right]^{+}\right)<T_{0}([\mathrm{BScB}]) . D_{0}$ and $E_{\mathrm{D}}$ for all the ions were found to increase with the increase in the salt concentration. This means that diffusivities as well as energy barriers for diffusion increases at higher salt contents.

When we compared the parameters for ionic conductivity (Table 2) and diffusivity (Table 3), some obvious similarities and differences were observed. $\sigma_{0}$ increased with the increase in the concentration of the $\mathrm{Li}[\mathrm{BScB}]$ salt in the IL that may mean that ionic conductivity is largely contributed by the $\mathrm{Li}[\mathrm{BScB}]$ salt rather than by the neat IL.

The effect of the $\mathrm{Li}[\mathrm{BScB}]$ salt concentration in the IL on the diffusion of $\mathrm{Li}^{+}$is shown in Fig. 6. It reveals a monotonous decrease in the $\mathrm{Li}^{+}$diffusion coefficient with an increase in the $\mathrm{Li}[\mathrm{BScB}]$ salt concentration in the IL. Generally, this trend is similar to the trend of diffusion of $\left[\mathrm{P}_{4,4,4,8}\right]^{+}$and $[\mathrm{BScB}]^{-}$ions with the increase in the $\mathrm{Li}[\mathrm{BScB}]$ concentration. The apparent transference numbers of the individual ions were determined from the self-diffusion coefficients of all the ions present in the electrolyte using the following equation, as previously reported. ${ }^{45,46}$

$$
t_{i}=\frac{x_{i} D_{i}}{\sum_{i} x_{i} D_{i}}
$$

where $t_{i}$ is the apparent transference number, $x_{i}$ is the molar fraction of an ion, and $D_{i}$ is the self-diffusion coefficient of an ion in $\mathrm{m}^{2} \mathrm{~s}^{-1}$. The apparent transference numbers of $\mathrm{Li}^{+},\left[\mathrm{P}_{4,4,4,8}\right]^{+}$, and $[\mathrm{BScB}]^{-}$ions for different concentrations and temperatures are tabulated in Table 4 . As expected, the transference number of $[\mathrm{BScB}]^{-}$anion is higher than that of $\left[\mathrm{P}_{4,4,4,8}\right]^{+}$cation at all the

Table 3 The VFT equation parameters and energies of activation for diffusion data for neat $\left[\mathrm{P}_{4,4,4,8}\right][\mathrm{BSCB}]$ and $\left[\mathrm{P}_{4,4,4,8}\right][\mathrm{BSCB}]$ with different concentrations of $\mathrm{Li}[\mathrm{BSCB}]$ salt (Fig. 5)

\begin{tabular}{llllll}
\hline $\begin{array}{l}\mathrm{Li}[\mathrm{BScB}] \\
(\mathrm{mol} \%)\end{array}$ & $\begin{array}{l}\text { Ion } \\
\text { diffusion }\end{array}$ & $\begin{array}{l}D_{0} \times 10^{-8} \\
\left(\mathrm{~m}^{2} \mathrm{~s}^{-1}\right)\end{array}$ & $B(\mathrm{~K})$ & $T_{0}(\mathrm{~K})$ & $\begin{array}{l}E_{\mathrm{D}} \\
\left(\mathrm{kJ} \mathrm{mol} \mathrm{K}^{-1}\right)\end{array}$ \\
\hline 2.5 & {$\left[\mathrm{P}_{4,4,4,8}\right]^{+}$} & $3.48 \pm 0.09$ & $1299 \pm 8$ & $188 \pm 10$ & $10.8 \pm 0.1$ \\
& {$\left[\mathrm{BScB}^{-}\right.$} & $4.33 \pm 0.05$ & $1311 \pm 13$ & $188 \pm 10$ & $10.9 \pm 0.1$ \\
& $\mathrm{Li}^{+}$ & $2.11 \pm 0.12$ & $1276 \pm 12$ & $188 \pm 10$ & $10.6 \pm 0.1$ \\
7.5 & & & & & \\
& $\mathrm{Li}^{+}$ & $2.52 \pm 0.02$ & $1365 \pm 4$ & $188 \pm 10$ & $11.3 \pm 0.1$ \\
15 & {$\left[\mathrm{P}_{4,4,4,8}\right]^{+}$} & $3.60 \pm 0.02$ & $1357 \pm 12$ & $188 \pm 10$ & $11.3 \pm 0.1$ \\
& {$\left[\mathrm{BScB}^{-}\right.$} & $4.50 \pm 0.16$ & $1400 \pm 13$ & $188 \pm 10$ & $11.6 \pm 0.1$ \\
& $\mathrm{Li}^{+}$ & $2.58 \pm 0.05$ & $1446 \pm 9$ & $188 \pm 10$ & $12.0 \pm 0.1$ \\
& & & & & \\
20 & {$\left[\mathrm{P}_{4,4,4,8}\right]^{+}$} & $3.71 \pm 0.07$ & $1368 \pm 15$ & $188 \pm 10$ & $11.4 \pm 0.1$ \\
& {$\left[\mathrm{BScB}^{-}\right.$} & $4.52 \pm 0.06$ & $1337 \pm 42$ & $188 \pm 10$ & $11.1 \pm 0.2$ \\
& $\mathrm{Li}^{+}$ & $2.73 \pm 0.34$ & $1419 \pm 13$ & $188 \pm 10$ & $11.8 \pm 0.1$
\end{tabular}

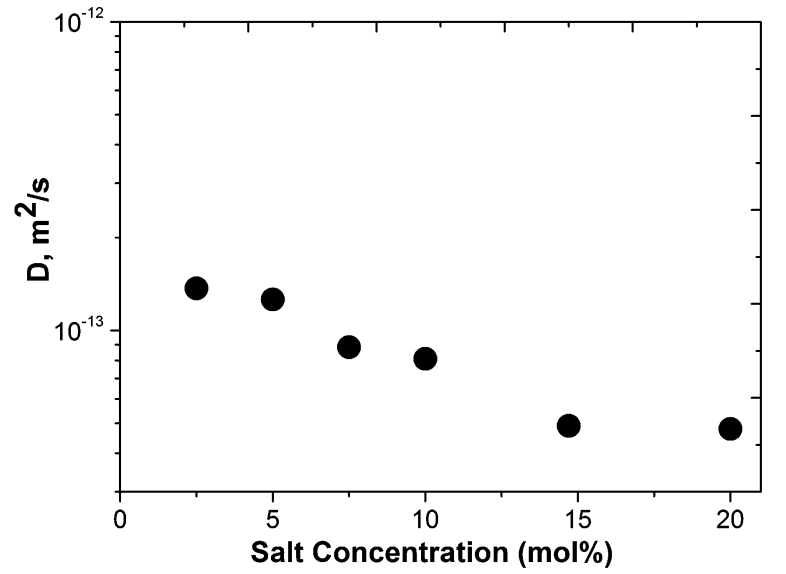

Fig. 6 Dependence of the $\mathrm{Li}^{+}$diffusion coefficient on the molar concentration of the $\mathrm{Li}[\mathrm{BSCB}]$ salt in $\left[\mathrm{P}_{4,4,4,8}\right][\mathrm{BSCB}] \mathrm{IL}$ at $295 \mathrm{~K}$.

Table 4 The apparent transference numbers of the individual ions for 2.5, 15 , and 20 mol\% of $\mathrm{Li}[\mathrm{BSCB}]$ salt in $\left[\mathrm{P}_{4,4,4,8}\right][\mathrm{BSCB}]$ at various temperatures

\begin{tabular}{|c|c|c|c|c|c|c|}
\hline \multirow[b]{2}{*}{$\mathrm{Li}[\mathrm{BScB}](\mathrm{mol} \%)$} & \multicolumn{3}{|l|}{$295 \mathrm{~K}$} & \multicolumn{3}{|c|}{$355 \mathrm{~K}$} \\
\hline & $t_{\mathrm{Li}}$ & $t_{[\mathrm{P4}, 4,4,8]^{+}}$ & $t_{[\mathrm{BScB}]^{-}}$ & $t_{\mathrm{Li}}$ & $t_{[\mathrm{P} 4,4,4,8]+}$ & $t_{[\mathrm{BScB}]^{-}}$ \\
\hline 2.5 & 0.009 & 0.452 & 0.539 & 0.009 & 0.447 & 0.545 \\
\hline 15 & 0.040 & 0.466 & 0.494 & 0.047 & 0.414 & 0.539 \\
\hline 20 & 0.040 & 0.355 & 0.606 & 0.054 & 0.384 & 0.562 \\
\hline
\end{tabular}

studied concentrations and temperatures. This is due to the larger size of the cation as compared to that of the anion. It was found that the transference number of $\mathrm{Li}^{+}$is nearly zero at $2.5 \mathrm{~mol} \%$ concentration of $\mathrm{Li}[\mathrm{BScB}]$ in the IL. However, this transference number of $\mathrm{Li}^{+}$is significantly enhanced at higher $\mathrm{Li}$ salt concentrations. The $\mathrm{Li}^{+}$transference numbers are obviously lower in these orthoborate-based IL electrolytes as compared to those in the IL electrolytes with halogenated anions. ${ }^{47-49}$

There are few plausible explanations for the lower transference number of $\mathrm{Li}^{+}$cation in the phosphonium orthoborate-based IL electrolytes. First is the relatively lower solubility (up to $20 \mathrm{~mol} \%$ ) of the $\mathrm{Li}[\mathrm{BSCB}]$ salt in the $\mathrm{IL}$ at room temperature. The lithium transference number can be significantly increased if larger amount of lithium salt is dissolved in the IL. Second, the size of the anion is much larger than those of the typical halogenated anions such as $\mathrm{BF}_{4}, \mathrm{PF}_{6}$, and $\mathrm{NTf}_{2}$. Third, the PFG NMR method underestimates the diffusion coefficients of the charged species. Martins et al. have calculated the lithium transference number in phosphonium-based ionic liquids using both NMR and electrochemical methods and have found that the values calculated from the electrochemical method are 2-3 fold larger than the values calculated from the NMR method. ${ }^{50}$ These authors have explained that NMR method underestimates the diffusion coefficient of charged species because it considers all the species and aggregates between lithium cation and the anion that are larger than the small charged $\mathrm{Li}^{+}$cation. Thus, their low diffusion coefficients decrease the overall diffusion coefficient and transference number of $\mathrm{Li}^{+}$cation.

${ }^{7} \mathrm{Li}$ NMR spectra of the $\mathrm{Li}[\mathrm{BScB}]$ salt dissolved in the $\left[\mathrm{P}_{4,4,4,8}\right][\mathrm{BSCB}] \mathrm{IL}$ demonstrate a single resonance line. The ${ }^{7} \mathrm{Li}$ 

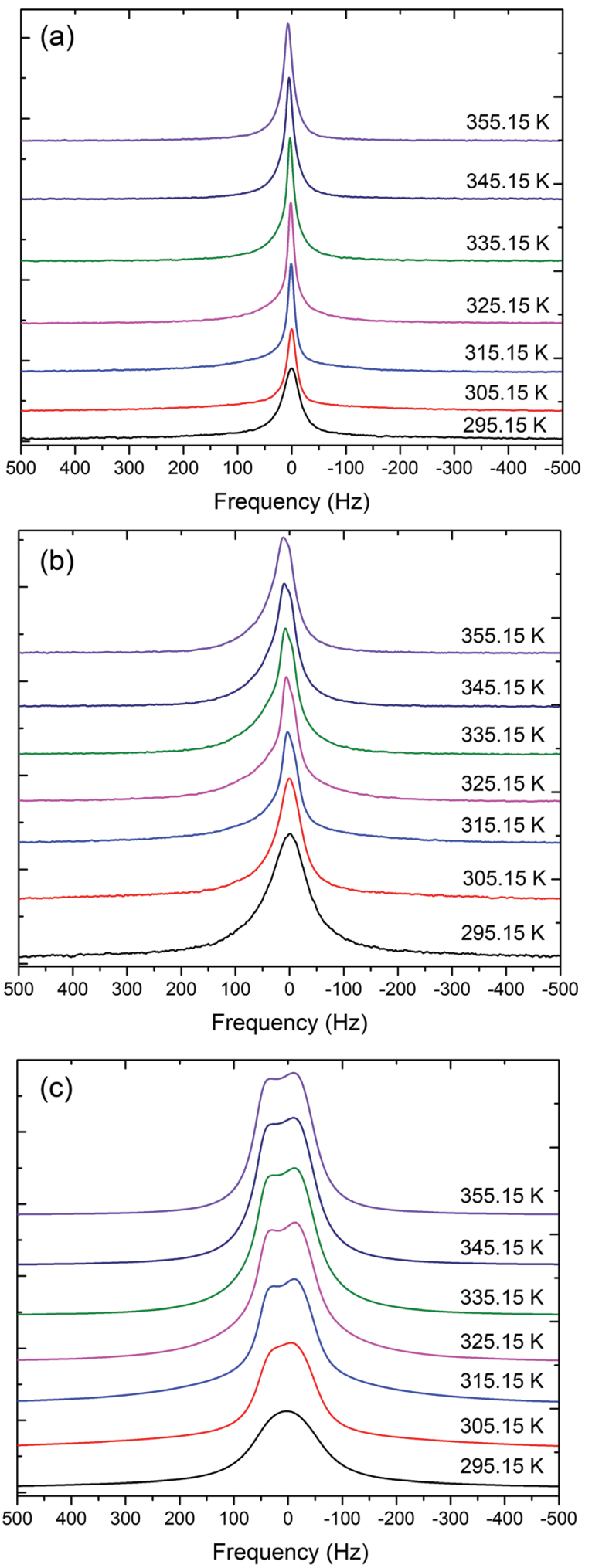

Fig. 7 The ${ }^{7}$ Li NMR spectra of (a) $2.5 \mathrm{~mol} \%$, (b) $15 \mathrm{~mol} \%$, and (c) $20 \mathrm{~mol} \%$ of $\mathrm{Li}[\mathrm{BSCB}]$ in $\left[\mathrm{P}_{4,4,4,8}\right][\mathrm{BSCB}]$.

NMR spectra for $2.5 \mathrm{~mol} \%, 15 \mathrm{~mol} \%$, and $20 \mathrm{~mol} \%$ electrolytes as a function of temperature are shown in Fig. 7. It was observed that the line broadening of the ${ }^{7} \mathrm{Li}$ NMR spectra increased with an increase in the concentration of the $\mathrm{Li}[\mathrm{BScB}]$ salt in the IL and decreased with an increase in temperature. For higher $\mathrm{Li}[\mathrm{BScB}]$ concentrations $(15 \mathrm{~mol} \%$ and $20 \mathrm{~mol} \%$ ), the value of $\Delta \omega$ increased by a factor of 3-4 than that for the lowest $(2.5 \mathrm{~mol} \%)$ salt concentration in the IL. Via increasing the concentration of $\mathrm{Li}[\mathrm{BScB}]$ salt in the IL, the ${ }^{7} \mathrm{Li}$ NMR resonance line is split into two lines. The splitting of the resonance line indicates that a cluster is being formed at the concentrations higher than $15 \mathrm{~mol} \%$ of Li salt in the IL. The splitting is more evident for $20 \mathrm{~mol} \%$ of Li salt, as shown in Fig. 7c. Interestingly, the splitting of the ${ }^{7} \mathrm{Li}$ NMR resonance line is more clearly seen at a temperature higher than $315.15 \mathrm{~K}$. It suggests that $\mathrm{Li}^{+}$cation has been transported between two different chemical environments with slightly different chemical shifts.

The ${ }^{7} \mathrm{Li}$ NMR spectral line broadening non-monotonously decreases as the temperature increases from $295 \mathrm{~K}$ to $355 \mathrm{~K}$. In the beginning of this temperature range (295-315 K), $\Delta \omega$ sharply decreases by factors of 1.2 for $2.5 \mathrm{~mol} \%$ and 1.9 for $15 \mathrm{~mol} \%$. However, above $315 \mathrm{~K}$, it reaches a plateau region as in the case of the $2.5 \mathrm{~mol} \%$ concentration or slowly and monotonously decreases further, as can be seen in the case of $20 \mathrm{~mol} \%$ concentration. A graphical representation of the variation of ${ }^{7} \mathrm{Li}$ NMR spectral line broadening with temperature for $2.5 \mathrm{~mol} \%$ and $20 \mathrm{~mol} \%$ concentrations of the $\mathrm{Li}[\mathrm{BScB}]$ salt in $\left[\mathrm{P}_{4,4,4,8}\right][\mathrm{BScB}]$ is shown in Fig. S8 in the ESI. $\dagger$

Chemical shift of the center of the line is slightly dependent on the $\mathrm{Li}[\mathrm{BScB}]$ concentration in the $\mathrm{IL}$, whereas it changes as the temperature increases (Fig. S9 in the ESI $\dagger$ ). The temperature dependence of the chemical shift demonstrates two regions with different behaviors. In the temperature range 295-310 K, no significant change in the chemical shift was observed. At higher temperatures, 310-355 K, the chemical shift almost linearly moved in the high-field side with temperature. Slopes of the linear dependences of chemical shift relative to the chemical shift value at $295 \mathrm{~K}$ are $\sim 1.16 \times 10^{-3} \mathrm{ppm} \mathrm{K}^{-1}$ for $2.5 \%$ of $\mathrm{Li}[\mathrm{BScB}]$ and $\sim 7.21 \times 10^{-4} \mathrm{ppm} \mathrm{K}^{-1}$ for $20 \%$ of $\mathrm{Li}[\mathrm{BScB}]$ in the IL. Thus, at 310-325 K, the chemical shift is higher for the system with $20 \%$ of $\mathrm{Li}[\mathrm{BScB}]$, whereas at $340-355 \mathrm{~K}$, the chemical shift is higher for the system with $2.5 \%$ of $\mathrm{Li}[\mathrm{BScB}]$.

FTIR spectroscopy was employed to obtain deeper insights into the interaction of $\mathrm{Li}^{+}$ion with the $[\mathrm{BScB}]^{-}$anion in these electrolytes. Fig. 8 shows the FTIR spectra of the neat $\left[\mathrm{P}_{4,4,4,8}\right][\mathrm{BScB}]$ and $\left[\mathrm{P}_{4,4,4,8}\right][\mathrm{BScB}]$ mixed with different concentrations of $\mathrm{Li}[\mathrm{BScB}]$ salt in the IL in the frequency range from $3150 \mathrm{~cm}^{-1}$ to $2700 \mathrm{~cm}^{-1}$ (Fig. 8a) and from $1800 \mathrm{~cm}^{-1}$ to $1250 \mathrm{~cm}^{-1}$ (Fig. 8b). A comparison of the FTIR spectra for neat $\left[\mathrm{P}_{4,4,4,8}\right][\mathrm{BScB}]$ and $\mathrm{Li}[\mathrm{BScB}]$ salt is shown in Fig. S10 in the ESI. $\dagger$ The stretching vibrations around $3050 \mathrm{~cm}^{-1}$ and in the frequency range from 3000 to $2850 \mathrm{~cm}^{-1}$ are assigned to the aromatic and aliphatic $\mathrm{C}-\mathrm{H}$ groups, respectively. The vibrations around $1700 \mathrm{~cm}^{-1}$ are assigned to $\mathrm{C}=\mathrm{O}$ stretching, those around $1600 \mathrm{~cm}^{-1}$ to the aromatic ring vibrations, and those between $1300 \mathrm{~cm}^{-1}$ and $1350 \mathrm{~cm}^{-1}$ are attributed to the B-O stretching. Obviously, no significant shift in the vibrations is observed in the FTIR spectra when $\mathrm{Li}[\mathrm{BScB}]$ salt is added to the $\left[\mathrm{P}_{4,4,4,8}\right][\mathrm{BScB}]$ IL. The $\mathrm{C}=\mathrm{O}$ stretching vibration around 

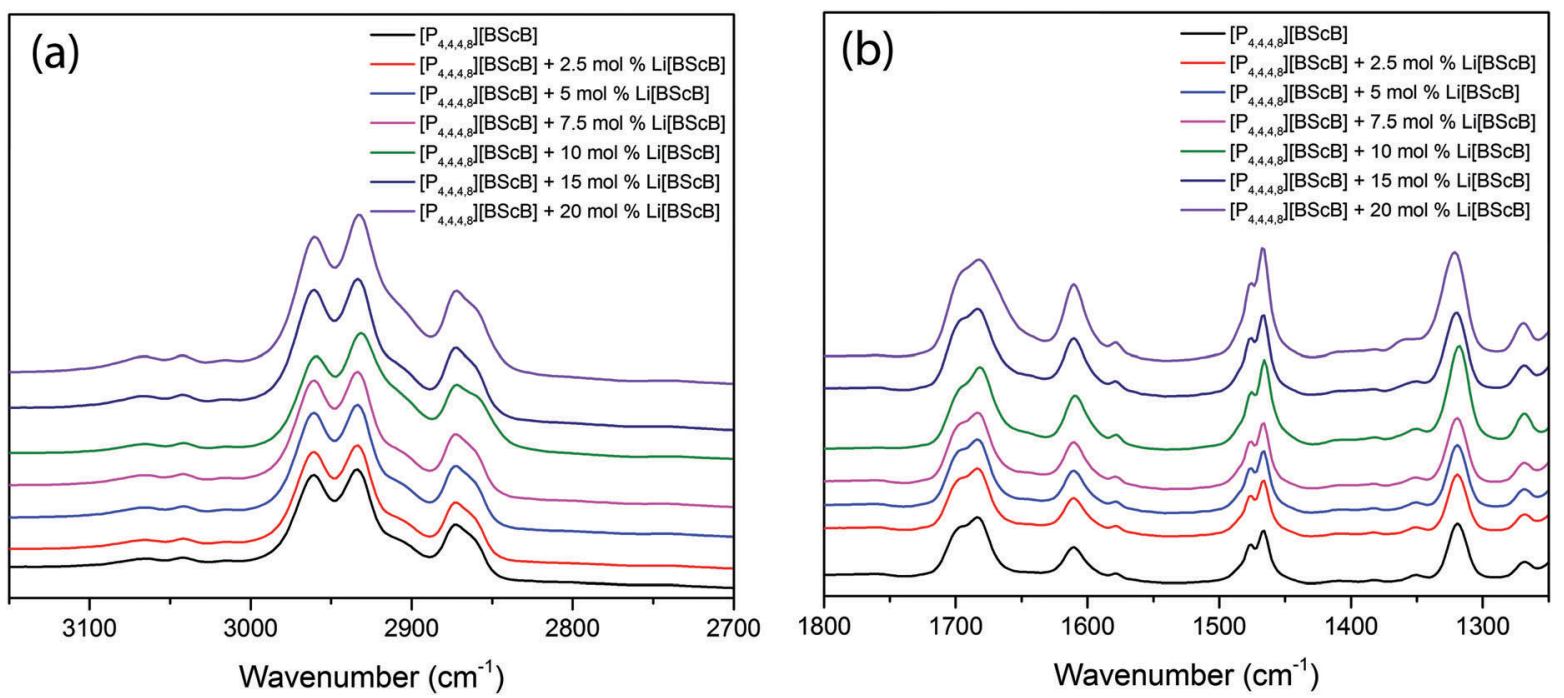

Fig. 8 FTIR spectra of neat $\left[\mathrm{P}_{4,4,4,8}\right][\mathrm{BSCB}]$ and $\left[\mathrm{P}_{4,4,4,8}\right][\mathrm{BSCB}]$ with different $\mathrm{Li}[\mathrm{BScB}]$ concentrations, as indicated (mol\%), in the frequency range (a) from $3150 \mathrm{~cm}^{-1}$ to $2700 \mathrm{~cm}^{-1}$ and (b) from $1800 \mathrm{~cm}^{-1}$ to $1250 \mathrm{~cm}^{-1}$.

$1700 \mathrm{~cm}^{-1}$ is slightly broader for the concentrations higher than $15 \mathrm{~mol} \%$ Li salt in the IL as compared that for lower concentrations, $<15 \mathrm{~mol} \%$. This broadness reveals dynamic interactions between $\mathrm{Li}^{+}$cations and $[\mathrm{BScB}]^{-}$anion.

Consistent with other studies, the measured ionic conductivity and diffusivities of the ions showed that overall ionic mobility increased with the increasing temperature and decreased with the increasing salt concentration in the IL. ${ }^{51-54}$ The NMR and FTIR measurements suggest strong dynamic interactions between $\mathrm{Li}^{+}$ cations and $[\mathrm{BScB}]^{-}$anions that are concentration and temperature dependent. The aromatic $[\mathrm{BScB}]^{-}$anion may be coordinated through the delocalized electrons, one oxygen atom or two, and/or may be coordinated to a single $\mathrm{Li}^{+}$cation or more. The strong dynamic interactions may lead to ionic clustering at higher concentrations of Li salt in the IL. Ionic clustering has been previously observed at higher concentrations of NaFSI salt in the C3mPyr ionic liquid. ${ }^{55}$

\section{Conclusions}

We investigated ion dynamics in halogen-free and hydrophobic orthoborate-based ionic liquid electrolytes. Tributyloctylphosphonium bis(salicylato)borate $\left[\mathrm{P}_{4,4,4,8}\right][\mathrm{BScB}] \mathrm{IL}$ and lithium bis(salicylato)borate $\mathrm{Li}[\mathrm{BScB}]$ salt were synthesized and characterized using ${ }^{1} \mathrm{H},{ }^{13} \mathrm{C},{ }^{31} \mathrm{P}$, and ${ }^{11} \mathrm{~B}$ NMR spectroscopy. It was found that the maximum solubility of the $\mathrm{Li}[\mathrm{BScB}]$ salt in $\left[\mathrm{P}_{4,4,4,8}\right][\mathrm{BScB}] \mathrm{IL}$ at room temperature is $20 \mathrm{~mol} \%$. The DSC data revealed a slight increase in the glass transition temperature upon the addition of the $\mathrm{Li}[\mathrm{BScB}]$ salt to the IL, suggesting stronger ion-ion interactions in the electrolytes. No significant effect on the thermal degradation is observed upon the addition of $\mathrm{Li}[\mathrm{BScB}]$ salt to the IL. An increase in the ionic conductivity is observed as a function of temperature and decrease is found with the addition of $\mathrm{Li}[\mathrm{BScB}]$ salt to the IL.
It revealed that the addition of lithium salts led to stronger Coulombic interactions between lithium cations and the anions that result in the decrease in the ionic mobility of the electrolytes. The PFG NMR data suggested that lithium ions were more mobile at higher temperatures and lower $\mathrm{Li}[\mathrm{BSCB}]$ concentrations. The ${ }^{7} \mathrm{Li}$ NMR resonance line is split into two lines at higher $\mathrm{Li}$ salt concentrations, suggesting dynamic interactions between lithium cation and the $[\mathrm{BScB}]^{-}$anion. ATR-FTIR spectroscopy revealed spectral line broadening for $\left[\mathrm{P}_{4,4,4,8}\right][\mathrm{BScB}]$ mixed with $\mathrm{Li}[\mathrm{BScB}]$ salt at concentrations higher than $15 \mathrm{~mol} \%$. This study will motivate researchers to design and synthesize new halogen-free and hydrolytically stable electrolytes to enhance the safety and performance of energy storage devices.

\section{Acknowledgements}

The Norrbotten Research Council (NoFo) and the Swedish Research Council are gratefully acknowledged for the financial support. NMR spectrometer, TGA, DSC, and Metrohm Autolab PGSTAT302N electrochemical workstation have been purchased from the funds raised by the Kempe Foundation and Lulea University of Technology. NMR measurements were partly carried out using the equipment of the Federal Centre of Collective Facilities of Kazan Federal University.

\section{References}

1 V. Etacheri, R. Marom, R. Elazari, G. Salitra and D. Aurbach, Challenges in the development of advanced Li-ion batteries: a review, Energy Environ. Sci., 2011, 4, 3243-3262.

2 L. Xia, L. $\mathrm{Yu}, \mathrm{D} . \mathrm{Hu}$ and G. Z. Chen, Electrolytes for electrochemical energy storage, Mater. Chem. Front., 2017, 1, 584-618. 
3 P. G. Bruce, S. A. Freunberger, L. J. Hardwick and J. M. Tarascon, $\mathrm{Li}_{-} \mathrm{O}_{2}$ and Li-S batteries with high energy storage, Nat. Mater., 2011, 11, 19-29.

$4 \mathrm{~K} . \mathrm{Xu}$, Electrolytes and interphases in Li-ion batteries and beyond, Chem. Rev., 2014, 114, 11503-11618.

5 E. Zinigrad, L. Larush-Asraf, J. Gnanaraj, M. Sprecher and D. Aurbach, On the thermal stability of $\mathrm{LiPF}_{6}$, Thermochim. Acta, 2005, 438, 184-191.

6 D. R. MacFarlane, N. Tachikawa, M. Forsyth, J. M. Pringle, P. C. Howlett, G. D. Elliott, J. H. Davis, Jr, M. Watanabe, P. Simon and C. A. Angell, Energy applications of ionic liquids, Energy Environ. Sci., 2014, 7, 232-250.

7 K. Seddon, Ionic liquids: designer solvents for green synthesis, Chem. Eng., 2002, 730, 33-35.

8 J. Hallett and T. Welton, Room-temperature ionic liquids: solvents for synthesis and catalysis, Chem. Rev., 2011, 111, 3508-3576.

9 N. Plechkova and K. Seddon, Applications of ionic liquids in the chemical industry, Chem. Soc. Rev., 2008, 37, 123-150.

10 J. H. Shin, W. A. Henderson and S. Passerini, Ionic liquids to the rescue? Overcoming the ionic conductivity limitations of polymer electrolytes, Electrochem. Commun., 2003, 5, 1016-1020.

11 M. Barghamadi, A. S. Best, A. I. Bhatt, A. F. Hollenkamp, M. Musameh, R. J. Rees and T. Ruther, Lithium-sulfur batteries-the solution is in the electrolyte, but is the electrolyte a solution?, Energy Environ. Sci., 2014, 7, 3902-3920.

12 H. Yoon, A. S. Best, M. Forsyth, D. R. MacFarlane and P. C. Howlett, Physical properties of high Li-ion content $N$-propyl- $N$-methylpyrrolidinium bis(fluorosulfonyl)imide based ionic liquid electrolytes, Phys. Chem. Chem. Phys., 2015, 17, 4656-4663.

13 M. Hilder, G. M. A. Girard, K. Whitbread, S. Zavorine, M. Moser, D. Nucciarone, M. Forsyth, D. R. MacFarlane and P. C. Howlett, Physicochemical characterization of a new family of small alkyl phosphonium imide ionic liquids, Electrochim. Acta, 2016, 202, 100-109.

14 S. N. Chavan, A. Tiwari, T. C. Nagaiah and D. Mandal, Ether and siloxane functionalized ionic liquids and their mixtures as electrolyte for lithium-ion batteries, Phys. Chem. Chem. Phys., 2016, 18, 16116-16126.

15 T. Yong, L. Zhang, J. Wang, Y. Mai, X. Yan and X. Zhao, Novel choline-based ionic liquids as safe electrolytes for high-voltage lithium-ion batteries, J. Power Sources, 2016, 328, 397-404.

16 S. Giri, S. Behera and P. Jena, Superhalogens as building blocks of halogen-free electrolytes in lithium-ion batteries, Angew. Chem., 2014, 126, 14136-14139.

17 A. Basile, H. Yoon, D. R. MacFarlane, M. Forsyth and P. C. Howlett, Investigating non-fluorinated anions for sodium battery electrolytes based on ionic liquids, Electrochem. Commun., 2016, 71, 48-51.

18 J. Barthel, M. Wuhr, R. Buestrich and H. J. Gores, A new class of electrochemically and thermally stable lithium salts for lithium battery electrolytes: I. Synthesis and properties of lithium bis[1,2-benzenediolato(2-)-O,O'] borate, J. Electrochem. Soc., 1995, 142, 2527-2531.
19 J. Barthel, R. Buestrich, E. Carl and H. J. Gores, A new class of electrochemically and thermally stable lithium salts for lithium battery electrolytes: III. Synthesis and properties of some lithium organoborates, J. Electrochem. Soc., 1996, 143, 3572-3575.

20 M. Handa, S. Fukuda, Y. Sasaki and K. Usami, Use of a chelate complex with boron as a lithium salt for lithium battery electrolytes, J. Electrochem. Soc., 1997, 144, L235-L237.

21 Z. M. Xue., Y. Z. Ding and C. H. Chen, A DFT study of electronic structures, energies, and molecular properties of lithium bis[croconato]borateand its derivatives, Electrochim. Acta, 2007, 53, 990-997.

22 Y. Sasaki, M. Handa, K. Kurashima, T. Tonuma and K. Usami, Application of lithium organoborate with salicylic ligand to lithium battery electrolyte, J. Electrochem. Soc., 2001, 148, A999-A1003.

23 D. Aurbach, J. S. Gnanaraj, W. Geissler and M. Schmidt, Vinylene carbonate and $\mathrm{Li}$ salicylatoborate as additives in $\mathrm{LiPF}_{3}\left(\mathrm{CF}_{2} \mathrm{CF}_{3}\right)_{3}$ solutions for rechargeable Li-ion batteries, J. Electrochem. Soc., 2004, 151, A23-A30.

24 L. Niedzicki, E. Karpierz, M. Zawadzki, M. Dranka, M. Kasprzyk, A. Zalewska, M. Marcinek, J. Zachara, U. Domanska and W. Wieczorek, Lithium cation conducting TDI anion-based ionic liquids, Phys. Chem. Chem. Phys., 2014, 16, 11417-11425.

25 P. Jankowski, W. Wieczorek and P. Johansson, New boron based salts for lithium-ion batteries using conjugated ligands, Phys. Chem. Chem. Phys., 2016, 18, 16274-16280.

26 C. Liao, K. S. Han, L. Baggetto, D. A. Hillesheim, R. Custelcean, E. S. Lee, B. Gue, Z. Bi, D. Jiang, G. M. Veith, E. W. Hagaman, G. M. Brown, C. Bridges, M. P. Paranthaman, A. Manthiram, S. Dai and X. G. Sun, Synthesis and characterization of lithium bis(fluoromalonato)borate for lithium-ion battery applications, Adv. Energy Mater., 2014, 4, 1301368.

27 K. Xu, S. S. Zhang, U. Lee, J. L. Allen and T. R. Jow, LiBOB: Is it an alternative salt for lithium ion chemistry?, J. Power Sources, 2005, 146, 79-85.

28 H. Saruwatari, T. Kuboki, T. Kishi, S. Mikoshiba and N. Takami, Imidazolium ionic liquids containing LiBOB electrolyte for lithium battery, J. Power Sources, 2010, 195, 1495-1499.

29 K. Xu, S. Zhang, T. R. Jow, W. Xu and C. A. Angell, LiBOB as salt for lithium-ion batteries: a possible solution for high temperature operation, Electrochem. Solid-State Lett., 2002, 5, A26-A29.

30 K. Amine, J. Liu, S. Kang, I. Belharouak, Y. Hyung, D. Vissers and G. Henriksen, Improved lithium manganese oxide spinel/graphite Li-ion cells for high-power applications, J. Power Sources, 2004, 129, 14-19.

31 J. Liu, Z. Chen, S. Busking, I. Belharouak and K. Amine, Effect of electrolyte additives in improving the cycle and calendar life of graphite/ $\mathrm{Li}_{1.1}\left[\mathrm{Ni}_{1 / 3} \mathrm{Co}_{1 / 3} \mathrm{Mn}_{1 / 3}\right]_{0.9} \mathrm{O}_{2}$ Li-ion cells, J. Power Sources, 2007, 174, 852-855.

32 K. Xu, S. Zhang, B. A. Poese and T. R. Jow, Lithium bis(oxalato)borate stabilizes graphite anode in propylene carbonate, Electrochem. Solid-State Lett., 2002, 5, A259-A262. 
33 M. Matsui, K. Dokko, Y. Akita, H. Munakata and K. Kanamura, Surface layer formation of $\mathrm{LiCoO}_{2}$ thin film electrodes in non-aqueous electrolyte containing lithium bis(oxalate)borate, J. Power Sources, 2012, 210, 60-66.

34 A. Swiderska-Mocek and D. Naparstek, Physical and electrochemical properties of lithium bis(oxalate)borate-organic mixed electrolytes in Li-ion batteries, Electrochim. Acta, 2016, 204, 69-77.

35 F. U. Shah, S. Glavatskih, D. R. MacFarlane, M. Forsyth and O. N. Antzutkin, Novel halogen-free chelated orthoboratephosphonium ionic liquids: synthesis and tribophysical properties, Phys. Chem. Chem. Phys., 2011, 13, 12865-12873.

36 P. T. Callaghan, Principles of nuclear magnetic resonance microscopy, Clarendon, Oxford, 1991.

37 J. E. Tanner, Use of the stimulated echo in NMR diffusion studies, J. Chem. Phys., 1970, 52, 2523-2526.

38 H. Yoon, H. Zhu, A. Hervault, M. Armand, D. R. MacFarlane and M. Forsyth, Physicochemical properties of $N$-propyl- $N$ methylpyrrolidinium bis(fluorosulfonyl) imide for sodium metal battery applications, Phys. Chem. Chem. Phys., 2014, 16, 12350-12355.

39 P. Johansson, Electronic structure calculations on lithium battery electrolyte salts, Phys. Chem. Chem. Phys., 2007, 9, 1493-1498.

$40 \mathrm{M}$. H. Cohen and D. Turnbull, Molecular transport in liquids and gases, J. Chem. Phys., 1959, 31, 1164-1169.

41 M. Galinski, A. Lewandowski and I. Stepniak, Ionic liquids as electrolytes, Electrochim. Acta, 2006, 51, 5567-5580.

42 C. R. Pope, M. Kar, D. R. MacFarlane, M. Armand, M. Forsyth and L. A. O'Dell, Ion dynamics in a mixedcation alkoxy-ammonium ionic liquid electrolyte for sodium device applications, ChemPhysChem, 2016, 17, 3187-3195.

43 P. Atkins and J. de Paula, Atkin's Physical Chemistry, Oxford University Press, 10th edn, 2014, p. 1008.

44 A. Noda, K. Hayamizu and M. Watanabe, Pulsed-gradient spinecho ${ }^{1} \mathrm{H}$ and ${ }^{19} \mathrm{~F}$ ionic diffusion coefficient, viscosity, and ionic conductivity of non-chloroaluminate room-temperature ionic liquids, J. Phys. Chem. B, 2001, 105, 4603-4610.

45 T. Frömling, M. Kunze, M. Schönhoff, J. Sundermeyer and B. Roling, Enhanced lithium transference numbers in ionic liquid electrolytes, J. Phys. Chem. B, 2008, 112, 12985-12990.

46 B. Gélinas, M. Natali, T. Bibienne, Q. P. Li, M. Dolle and D. Rochefort, Electrochemical and transport properties of ions in mixtures of electroactive ionic liquid and propylene carbonate with a lithium salt for lithium-ion batteries, J. Phys. Chem. C, 2016, 120, 5315-5325.

47 A. Fernicola, F. Croce, B. Scrosati, T. Watanabe and H. Ohno, LiTFSI-BEPyTFSI as an improved ionic liquid electrolyte for rechargeable lithium batteries, J. Power Sources, 2007, 174, 342-348.

48 H. Yoon, P. C. Howlett, A. S. Best, M. Forsyth and D. R. MacFarlane, Fast charge/discharge of $\mathrm{Li}$ metal batteries using an ionic liquid electrolyte, J. Electrochem. Soc., 2013, 160, A1629-A1637.

49 H. B. Han, K. Liu, S. W. Feng, S. S. Zhou, W. F. Feng, J. Nie, H. Li, X. J. Huang, H. Matsumoto, M. Armand and Z. B. Zhou, Ionic liquid electrolytes based on multi-methoxyethyl substituted ammoniums and perfluorinated sulfonimides: preparation, characterization, and properties, Electrochim. Acta, 2010, 55, 7134-7144.

50 V. L. Martins, N. Sanchez-Ramirez, M. C. C. Ribeiro and R. M. Torresi, Two phosphonium ionic liquids with high $\mathrm{Li}^{+}$ transport number, Phys. Chem. Chem. Phys., 2015, 17, 23041-23051.

51 G. M. A. Girard, M. Hilder, H. Zhu, D. Nucciarone, K. Whitbread, S. Zavorine, M. Moser, M. Forsyth, D. R. MacFarlane and P. C. Howlett, Electrochemical and physicochemical properties of small phosphonium cation ionic liquid electrolytes with high lithium salt content, Phys. Chem. Chem. Phys., 2015, 17, 8706-8713.

52 M. Kerner, N. Plylahan, J. Scheers and P. Johansson, Ionic liquid based lithium battery electrolytes: fundamental benefits of utilising both TFSI and FSI anions?, Phys. Chem. Chem. Phys., 2015, 17, 19569-19581.

53 M. Forsyth, G. M. A. Girard, A. Basile, M. Hilder, D. R. MacFarlane, F. Chen and P. C. Howlett, Inorganic-organic ionic liquid electrolytes enabling high energy-density metal electrodes for energy storage, Electrochim. Acta, 2016, 220, 609-617.

54 S. Horiuchi, M. Yoshizawa-Fujita, Y. Takeoka and M. Rikukawa, Physicochemical and electrochemical properties of $N$-methylnmethoxymethylpyrrolidinium bis(fluorosulfonyl)amide and its lithium salt composites, J. Power Sources, 2016, 325, 637-640.

55 M. Forsyth, H. Yoon, F. Chen, H. Zhu, D. R. MacFarlane, M. Armand and P. C. Howlett, Novel $\mathrm{Na}^{+}$ion diffusion mechanism in mixed organic-inorganic ionic liquid electrolyte leading to high $\mathrm{Na}^{+}$transference number and stable, high rate electrochemical cycling of sodium cells, J. Phys. Chem. C, 2016, 120, 4276-4286. 